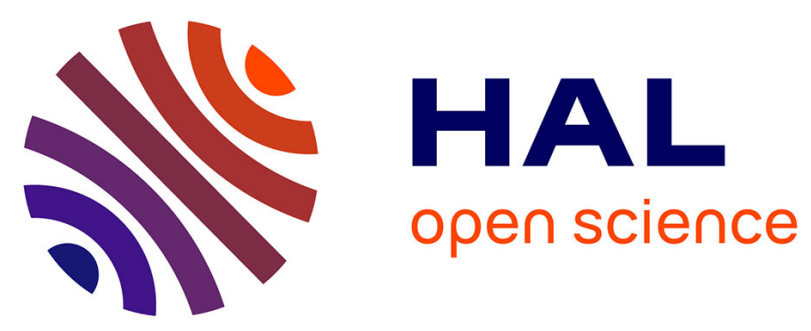

\title{
Optimal GNSS Acquisition Parameters when Considering Bit Transitions
}

Myriam Foucras, Bertrand Ekambi, Fayaz Bacard, Olivier Julien, Christophe Macabiau

\section{- To cite this version:}

Myriam Foucras, Bertrand Ekambi, Fayaz Bacard, Olivier Julien, Christophe Macabiau. Optimal GNSS Acquisition Parameters when Considering Bit Transitions. IEEE/ION PLANS 2014, Position Location and Navigation Symposium, May 2014, Monterey, United States. pp xxxx. hal-00989838

\section{HAL Id: hal-00989838 \\ https://hal-enac.archives-ouvertes.fr/hal-00989838}

Submitted on 19 May 2014

HAL is a multi-disciplinary open access archive for the deposit and dissemination of scientific research documents, whether they are published or not. The documents may come from teaching and research institutions in France or abroad, or from public or private research centers.
L'archive ouverte pluridisciplinaire HAL, est destinée au dépôt et à la diffusion de documents scientifiques de niveau recherche, publiés ou non, émanant des établissements d'enseignement et de recherche français ou étrangers, des laboratoires publics ou privés. 


\section{Optimal GNSS Acquisition Parameters when Considering Bit Transitions}

\author{
Myriam FOUCRAS, \\ Bertrand EKAMBI, Fayaz BACARD \\ ABBIA GNSS Technologies \\ Toulouse, France \\ myriam.foucras@abbia.fr
}

\author{
Olivier JULIEN, Christophe MACABIAU \\ Ecole Nationale de l'Aviation Civile (ENAC) \\ Toulouse, France
}

\begin{abstract}
This article focuses on the bit sign transition and its impact on the acquisition performance in terms of probability of detection. To do so, a theoretical study on the correlation process considering bit sign transition is done leading to the expression of the probability of detection, expressed in function of the bit transition location. Based on this, Monte-Carlo simulations were run to determine the acquisition performance degradations in terms of sensitivity losses and probability of detection for several GNSS civil signals. This allows determining the optimal acquisition parameters when bit sign transitions are considered during the acquisition process.
\end{abstract}

Keywords-Acquisition; Bit sign transition; Probability of detection

\section{I.INTRODUCTION}

In GNSS receivers, the acquisition process, the first stage of the signal processing module, consists in assessing the presence of GNSS signals and providing a rough estimation of the incoming signal parameters: the Doppler frequency and the code delay. To detect the presence of the signal, the received signal is correlated with a succession of locally generated replicas until the acquisition detector crosses a predefined threshold. One criteria of acquisition performance is the probability of detection which is the probability to detect the signal when the parameters of the local replica are (close to be) correct. This probability should be as high as possible but under unfavorable conditions, such as adverse environments, the detection becomes a challenge.

Initially, the GNSS signals were only defined on one component (such as GPS L1 C/A) but the new generation of signals has two components (such as GPS L1C, GPS L5, Galileo E1 OS, Galileo E5a/b...). One component referred to as data component contains the navigation message which can be seen as a random binary sequence from the point of view of the acquisition process. The other component is the pilot component, which does not carry any useful information but is modulated by a secondary code which is a known short binary sequence. For the acquisition process, with no aid and a priori information, the position of the bit transition on both components is not known and this implies considerable degradation on the acquisition performance as it was already presented by authors in [1].
The introduction of the pilot component and then the split of the total signal power between two components impact the way to process such a signal. Indeed, depending on the objective, these composite signals can be acquired by using correlator outputs based on one of the two components or based on both components. Considering the bit transition problem, one can wonder what the most suitable acquisition technique is, as when using both components, transitions can occur on both components.

The general context of this study is to acquire GNSS signals with a received $\mathrm{C} / \mathrm{N}_{0}$ (carrier to noise ratio) of $27 \mathrm{~dB}$ $\mathrm{Hz}$ but with a high probability of detection (95\%). As often neglected in the literature, a first work was done assuming that the data bits are constant during the correlation operation. The second step consists in studying the acquisition assuming no constancy because there is no reason that the integration interval is aligned with the data bit. Then, the motivations behind the presented investigation are to study the impact of the bit transition on the GNSS signals acquisition and provide optimal acquisition parameters accordingly. To do so, the mathematical model of the acquisition detector in presence of bit transitions is developed in order to express the probability of detection in presence of bit transitions. This is applied to a number of GNSS signals. Based on this, Monte-Carlo simulations were run to determine the optimal acquisition parameters which choice clearly depends on the received $\mathrm{C} / \mathrm{N}_{0}$, the signal structure and the acquisition technique using one or both components for two-component signals. This study is led for different GNSS signals which present feature differences in signal structure.

The article is divided into the following sections:

- A first section serves as a review of the GNSS signals and the acquisition process when the bit transition is not considered.

- The second section is dedicated to the mathematical model of the correlator outputs and then the probabilities of detection in presence of bit sign transitions.

- The following section, based on Matlab simulations presents the acquisition performance losses in terms of probability of detection due to bit transitions and optimal acquisition parameters 
- The last section concludes the paper remaining the main points of interest and results.

\section{GNSS SIGNALS AND ACQUISITION MODELS}

\section{A. GNSS signals' model}

In the case of this study, four GNSS signals are considered: GPS L1 C/A, GPS L1C, GPS L5 and Galileo E1 OS.

Table I and [2] summarize the main technical features needed for this study.

TABLE I. SignAL FEATURES

\begin{tabular}{|c|c|c|c|c|c|}
\hline Signal & $\begin{array}{l}\text { Nb of } \\
\text { comp } \\
\text { Power } \\
\end{array}$ & Modulation & $\begin{array}{l}\text { PRN code } \\
\text { length }\end{array}$ & $\begin{array}{c}\text { Data } \\
T_{d}\end{array}$ & $\begin{array}{c}\text { Secondary } \\
\text { code } \\
T_{p} \\
\end{array}$ \\
\hline $\begin{array}{c}\text { GPS } \\
\text { L1 C/A }\end{array}$ & 1 & BPSK & $\begin{array}{l}1023 \text { chips } \\
T_{c}=1 \mathrm{~ms}\end{array}$ & $20 \mathrm{~ms}$ & None \\
\hline $\begin{array}{l}\text { GPS } \\
\text { L1C }\end{array}$ & $\begin{array}{c}2 \\
\text { Data: } 25 \% \\
\text { Pilot: } 75 \%\end{array}$ & $\begin{array}{c}\text { TMBOC } \\
(6,1,1 / 11)\end{array}$ & $\begin{array}{c}10230 \\
\text { chips } \\
T_{c}=10 \mathrm{~ms}\end{array}$ & $10 \mathrm{~ms}$ & $\begin{array}{l}\text { Pilot } \\
10 \mathrm{~ms}\end{array}$ \\
\hline $\begin{array}{l}\text { GPS } \\
\text { L5 }\end{array}$ & $\begin{array}{c}2 \\
\text { Data: } 50 \% \\
\text { Pilot: } 50 \%\end{array}$ & BPSK & $\begin{array}{c}10230 \\
\text { chips } \\
T_{c}=1 \mathrm{~ms}\end{array}$ & $10 \mathrm{~ms}$ & $\begin{array}{c}\text { Data: } \mathrm{NH}_{10} \\
1 \mathrm{~ms} \\
\text { Pilot: } \mathrm{NH}_{20} \\
1 \mathrm{~ms}\end{array}$ \\
\hline $\begin{array}{l}\text { Galileo } \\
\text { E1 OS }\end{array}$ & $\begin{array}{c}2 \\
\text { Data: } 50 \% \\
\text { Pilot: } 50 \% \\
\end{array}$ & $\begin{array}{c}\text { CBOC } \\
(6,1,1 / 11)\end{array}$ & $\begin{array}{l}4092 \text { chips } \\
T_{c}=4 \mathrm{~ms}\end{array}$ & $4 \mathrm{~ms}$ & $\begin{array}{l}\text { Pilot } \\
4 \mathrm{~ms}\end{array}$ \\
\hline
\end{tabular}

Where

- $T_{c}$ is the spreading code (PRN) period

- $T_{d}$ is the data bit duration

- $T_{p}$ is the secondary code bit duration

A bit transition is defined as the transition between 2 consecutive bits and during a bit transition, a sign transition can occur or not as illustrated in Fig. 1.

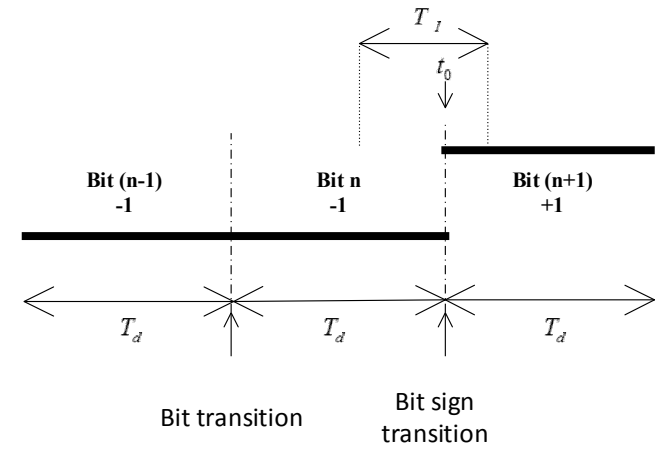

Fig. 1: Bit sign transition scheme

\section{1) GPS L1 C/A signal}

The GPS L1 C/A signal is a unique data component [3]. The GPS L1 C/A signal acquisition performance depends on the correlation duration. Indeed, because the data bit duration is twenty times longer than the spreading code period, it is possible to use as correlation durations an integer divider of the data bit duration such as $1,2,4,5,10$ or $20 \mathrm{~ms}$ [4].
The expression of the received GPS L1 C/A signal at the correlator input is:

$$
\begin{gathered}
r_{L 1 C / A}(t)= \\
A_{d} d(t-\tau) c_{1, d}(t-\tau) \cos \left(2 \pi\left(f_{I F}+f_{d}\right) t+\phi_{0}\right)+n(t)
\end{gathered}
$$

Where

- $\quad c_{1, x}$ designs the spreading code on the data component when $x$ stands for " $d$ " or on the pilot component for $x$ standing for " $p$ "

- $A_{d}=\sqrt{2 C}$ is the amplitude of signal and $C$ is the total signal power at the correlator input

- $\quad d$ is the data sequence

- $f_{I F}$ is the intermediate frequency

- $f_{d}$ is the incoming Doppler frequency

- $\tau$ is the incoming code delay

- $n$ is the incoming noise which is assumed to be a white noise with centered Gaussian distribution with a constant two-sided power spectral density equal to $N_{0} / 2 \mathrm{dBW} / \mathrm{Hz}$

- $\phi_{0}$ is the initial phase

\section{2) GPS L1C signal}

The GPS L1C signal, defined in [5], provides a number of advanced features including a power difference in both components: $75 \%$ of power in the pilot component for enhanced signal tracking and $25 \%$ of power in the data component. At the end, the received signal is represented as follows (in-phase representation because the relationship between the two components is not yet specified [6]):

$$
\begin{aligned}
r_{L 1 C}(t)=\left[\begin{array}{c}
A_{d} d(t-\tau) c_{1, d}(t-\tau) p_{B O C}(1) \\
+
\end{array}(t-\tau)\right. \\
+A_{p} c_{2}(t-\tau) c_{1, P}(t-\tau) p_{\text {TMBOC }}(t-\tau) \\
\times \cos \left(2 \pi\left(f_{L}+f_{d}\right) t+\phi_{0}\right)+n(t)
\end{aligned}
$$

Where

- $A_{d}=\sqrt{\frac{1}{2} C}$ and $A_{p}=\sqrt{\frac{3}{2} C}$ are the amplitudes of the received signal on the data and pilot components respectively

- $\quad c_{2}$ is the secondary code on the pilot component

- $p_{B O C}$ and $P_{\text {TMвоC }}$ are the subcarriers, which are defined by:

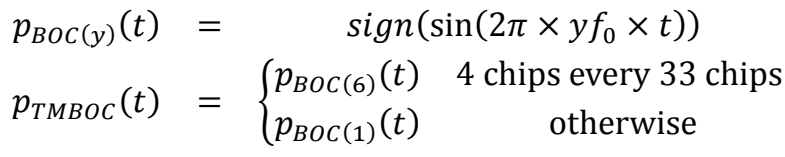

With $f_{0}=1.023 \mathrm{MHz}$.

On the data component, the probability of a bit sign transition, noted as $p_{d}$, is assumed to be $50 \%$. On the pilot component, the probability of a bit sign transition depends on the secondary code structure. For the GPS L1C signal, there are 63 secondary codes of 1800 bits that were defined. For each one, the probability of a bit sign transition is given in Fig. 2. As it can be observed, the probability of a bit sign transition on the pilot component noted as $p_{p}$ is close to 0.5 . In this work, it is assumed that for all of the GPS L1C secondary codes, $p_{p}=0.5$. 


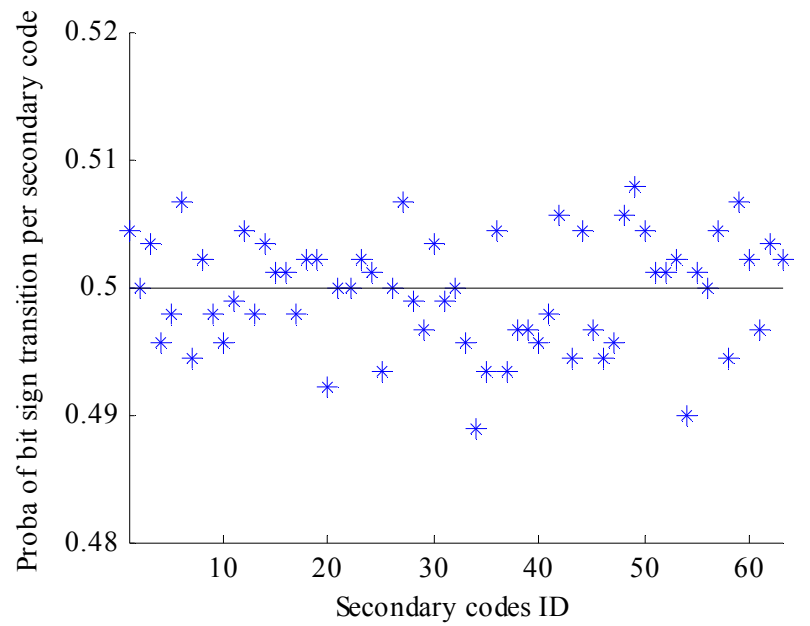

Fig. 2: Probability of bit transition on the GPS L1C pilot component in one secondary code period

\section{3) GPS L5 signal}

The GPS L5 signal presents the particularity to also have a secondary code of length 10 bits (Neuman-Hofman) on the data component, $\mathrm{NH}_{10}$. The two components are in quadrature [7] as it can be seen with its expression:

$$
r_{L 5}(t)=
$$

$A_{d} d(t-\tau) N H_{10}(t-\tau) c_{1, d}(t-\tau) \cos \left(2 \pi\left(f_{I F}+f_{d}\right) t+\phi_{0}\right)$

$+A_{p} N H_{20}(t-\tau) c_{1, p}(t-\tau) \sin \left(2 \pi\left(f_{I F}+f_{d}\right) t+\phi_{0}\right)+n(t)$

Where $A_{d}=A_{p}=\sqrt{C}$ and $c_{2, P}=N H_{20}$.

On the GPS L5 pilot component, the secondary NeumanHofman code is unique for all signals and contains 20 bits (Fig. 3). As it can be observed, the probability of bit sign transition on the pilot component is 0.5 .

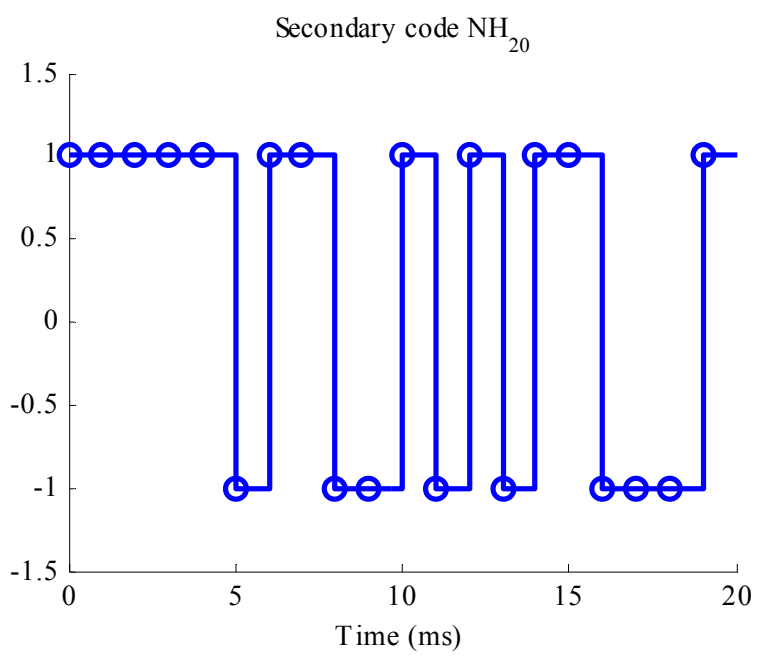

Fig. 3: GPS L5 secondary code on the pilot component

On the data component, the product of the data sequence and the $\mathrm{NH}$ will be seen as a data sequence with an increased rate (Fig. 4).

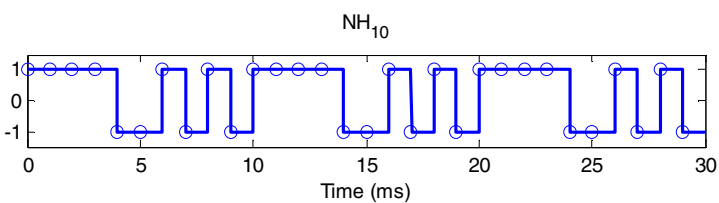

Dat

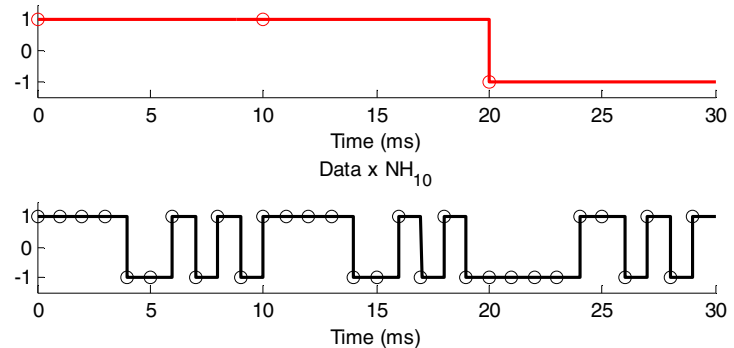

Fig. 4: The product of the data sequence and secondary code on the data component results in a binary sequence with a rate of $1 \mathrm{kbit} / \mathrm{s}$

This implies a non-uniform distribution of the bit sign transition. Knowing that there is a sign transition between the last and the first secondary code bits and that the data bit can change of sign during the $\mathrm{NH}_{10}$ period change, the probability of a bit sign transition on the data component is:

$$
\left\{\begin{array}{c}
p_{d}=\frac{1}{10}\left(1 \times \frac{1}{2}+9 \times \frac{5}{9}\right)=0.55 \\
p_{p}=\overline{p_{p}}=\frac{1}{2}
\end{array}\right.
$$

The Galileo E5a and E5b signals have the same features as the GPS L5 signal but the probabilities $p_{d}$ and $p_{p}$ are not equal to $1 / 2$ due to the presence of secondary codes on both components, as illustrated in Fig. 5 for the pilot component. In the following, the Galileo E5 a/b acquisition performance is not presented but seems to be relatively equivalent as GPS L5.

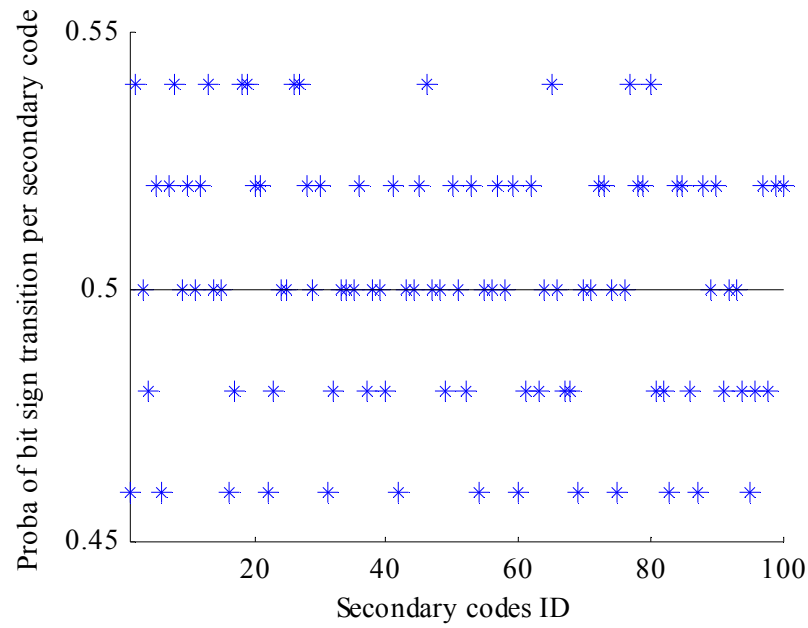

Fig. 5: Probability of Galileo E5 secondary code bit sign transition in one spreading code period 


\section{4) Galileo E1 OS signal}

Galileo E1 OS differs from GPS signals by its spreading code period which is equal to $4 \mathrm{~ms}$ (for 4092 chips) instead of $1 \mathrm{~ms}$ (GPS L1 C/A and GPS L5) or $10 \mathrm{~ms}$ (GPS L1C). It is defined in [8] and the received signal expression is:

$$
r_{E 1}(t)=\left[\begin{array}{c}
A_{d} \times d(t-\tau) c_{1, d}(t-\tau) p_{C B O C, d}(t-\tau) \\
-A_{p} \times c_{2}(t-\tau) c_{1, p}(t-\tau) p_{C B O C, p}(t-\tau)
\end{array}\right]
$$

Where

- $A_{d}=A_{p}=\sqrt{C}$

- $\quad p_{C B O C, d}$ and $p_{C B O C, p}$ are the subcarriers on the data and pilot components defined by:

$$
\begin{aligned}
& p_{C B O C, d}(t)=\frac{\sqrt{10}}{\sqrt{11}} p_{B O C(1)}(t)+\frac{1}{\sqrt{11}} p_{B O C(6)}(t) \\
& p_{C B O C, p}(t)=\frac{\sqrt{10}}{\sqrt{11}} p_{B O C(1)}(t)-\frac{1}{\sqrt{11}} p_{B O C(6)}(t)
\end{aligned}
$$

The secondary code on the pilot component is a unique 25bit code, represented on Fig. 6. Due to its number of bits (an odd number), the probability of a secondary code bit sign transition is $p_{p}=\frac{12}{25}=0.48$. In the following, $p_{p}=0.5$ is assumed.

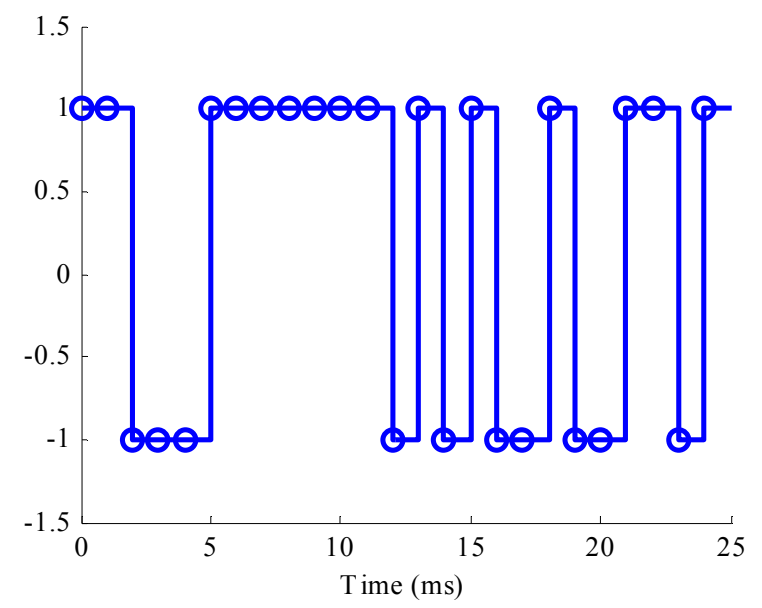

Fig. 6: Galileo E1 OS secondary code

\section{B. Correlator output in absence of data}

Usually GNSS receivers generate a local replica of the incoming signal depending on the estimation of the code delay $\hat{\tau}$ and Doppler frequency $\widehat{f}_{d}$.

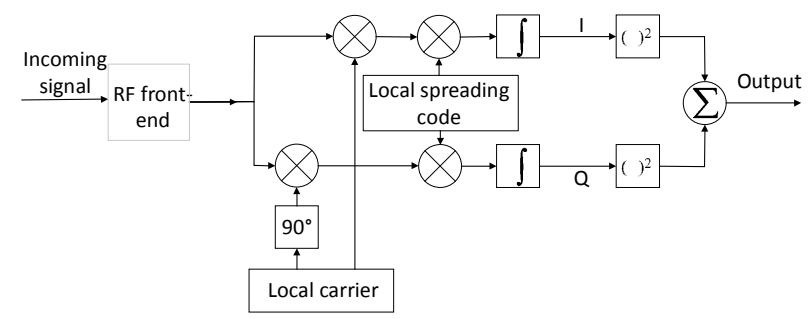

Fig. 7: Correlation process scheme
As illustrated in Fig. 7, the correlation process between the incoming signal and the local replica of one component provides in-phase $I$ and quadrature $Q$ correlator outputs. It is considered that the correlation operation for one component of the GNSS signal and assuming that:

- There is no data bit sign transition during the correlation process (ideal case)

- The correlation operation lasts for $T_{I}$ seconds

- The parameters of the processed signal and the local replica are constant during the correlation operation such that the code delay error $\varepsilon_{\tau}$ and the Doppler frequency error $\varepsilon_{f}$ are constant and the carrier phase error at the beginning of the correlation process is $\varepsilon_{\phi_{0}}$

The in-phase and quadrature-phase correlator outputs can thus be modelled as:

$$
\begin{aligned}
I_{x}(k) & =\frac{A_{x}}{2} R_{x}\left(\varepsilon_{\tau}\right) \cos \left(\pi \varepsilon_{f} T_{I}+\varepsilon_{\phi_{0}}\right) \operatorname{sinc}\left(\pi \varepsilon_{f} T_{I}\right)+n_{I_{x}}(k) \\
Q_{x}(k) & =\frac{A_{x}}{2} R_{x}\left(\varepsilon_{\tau}\right) \sin \left(\pi \varepsilon_{f} T_{I}+\varepsilon_{\phi_{0}}\right) \operatorname{sinc}\left(\pi \varepsilon_{f} T_{I}\right)+n_{Q_{x}}(k)
\end{aligned}
$$

Where

- $n_{I_{x}}$ and $n_{Q_{x}}$ are the noises at the correlator outputs which follow a centered Gaussian distribution and their variances are $\sigma^{2}=\frac{N_{0}}{4 T_{I}}[9]$

- $R_{x}$ is the autocorrelation function

Assuming a local BOC $(1,1)$ generation in this work, there is no distinction between the data autocorrelation and the pilot one for data/pilot signals. Moreover, the cross-correlation between the data and pilot spreading codes is assumed to be negligible due to the choice of the spreading codes as orthogonal as possible.

\section{Acquisition process in absence of data}

\section{1) Acquisition based on one component}

For signals with data and pilot components, an acquisition method consists in acquiring only one component or in considering both components to not suffer from a signal power loss. For the acquisition based on one component -and then the acquisition of the GPS L1 C/A signal- and for $K$ non-coherent summations, the acquisition detector is:

$$
T_{x}=\sum_{k=1}^{K}\left(I_{x}^{2}(k)+Q_{x}^{2}(k)\right)
$$

The acquisition process can be seen as a detection problem [10] because the purpose of the acquisition is to detect whether or not a signal from a given satellite is present at the receiver level. The hypothesis test based on Neyman-Pearson theorem, fully presented in [11] and only briefly described here, can be modelled as: the null hypothesis $H_{0}$ assumes that the useful signal is absent whereas the alternative hypothesis $H_{1}$ assumes that the useful signal is present and the signal parameters are well estimated. Then, the acquisition detection problem compares the acquisition detector with a threshold denoted $T_{h}$. The signal is declared present for a crossing of the threshold. 
The acquisition detector under the null and alternative hypothesis follows:

$$
\begin{array}{ccc}
\frac{T_{H_{0}}}{\sigma^{2}} & \sim_{H_{0}} & \chi^{2}(2 K) \\
\frac{T_{H_{1}}}{\sigma^{2}} & \sim_{H_{1}} & \chi^{2}\left(2 K, K \times \lambda_{0,0, x}\right)
\end{array}
$$

Where $\lambda_{n, t, x}$ is the non-centrality parameter ( $n$ designs the number of bit sign transitions occurring at $t$ )

Under the null hypothesis, the normalized acquisition detector $\frac{T_{H_{0}}}{\sigma^{2}}$ follows a chi-square distribution with $2 K$ degrees of freedom. The threshold can thus be determined knowing the desired probability of false alarm $P_{f a}(11), P_{f a}$ is set in this study to $10^{-3}$ as in [12].

$$
\begin{gathered}
P_{f a}=P_{H_{0}}\left(\frac{T_{H_{0}}}{\sigma^{2}}>T_{h}\right)=1-\mathcal{F}_{\chi^{2}(2 K)}\left(T_{h}\right) \\
P_{D}=P_{H_{1}}\left(\frac{T_{H_{1}}}{\sigma^{2}}>T_{h}\right)=1-\mathcal{F}_{\chi^{2}\left(2 K, \lambda_{0,0, x}\right)}\left(T_{h}\right)
\end{gathered}
$$

Where $\mathcal{F}_{\chi^{2}\left(2 K, \lambda_{0,0, x}\right)}$ is the cumulative distribution function of a chi-square distribution with $2 K$ degrees of freedom and a noncentrality parameter $\lambda_{0,0, x}$.

Under the alternative hypothesis $H_{1}$, the probability of detection $P_{D}$ can be determined because the normalized acquisition detector $\frac{T_{H_{1}}}{\sigma^{2}}$ is a non-central chi-square distribution with $2 K$ degrees of freedom and with a non-centrality parameter $K \times \lambda_{0,0, x}$ with the parameter $\lambda_{0,0, x}$ :

$$
\begin{aligned}
\lambda_{0,0, x} & =\left(E\left[\frac{I_{x}(k)}{\sigma^{2}}\right]\right)^{2}+\left(E\left[\frac{Q_{x}(k)}{\sigma^{2}}\right]\right)^{2} \\
& =\frac{A_{x}^{2}}{N_{0}} T_{I} R_{x}^{2}\left(\varepsilon_{\tau}\right) \operatorname{sinc}^{2}\left(\pi \varepsilon_{f} T_{I}\right)
\end{aligned}
$$

\section{2) Acquisition based on both components}

For the acquisition based on both components, the data and pilot components of the received signal are correlated separately with the local spreading codes of the data and pilot components [13]. The acquisition detector is then the sum of the two squared correlator outputs pairs given by the data and pilot components:

$$
T=\sum_{k=1}^{K}\left(I_{d}^{2}(k)+Q_{d}^{2}(k)+I_{p}^{2}(k)+Q_{p}^{2}(k)\right)
$$

Under the null and alternative hypothesis, the normalized acquisition detectors are chi-square distributions with $4 K$ degrees of freedom.

$$
\begin{aligned}
& \frac{T_{H_{0}}}{\sigma^{2}} \sim \chi^{2}(4 K) \\
& \frac{T_{H_{1}}}{\sigma^{2}} \sim \chi^{2}(4 K, \lambda)
\end{aligned}
$$

The non-centrality parameter under $H_{1}$ is the sum of the square expectations of the data and pilot correlator outputs $\lambda_{0,0}=K\left(\lambda_{0,0, d}+\lambda_{0,0, p}\right)$.

\section{BIT SIGN TRANSITION}

In reality, during the acquisition process, with no a priori information, there is no reason that the integration is aligned with the data bits since the receiver has not yet achieved bit synchronization. If this assumption is no longer considered, the present results become radically different. The following section intends to develop the associated mathematical model and to understand the impact of bit sign transitions on the acquisition of GNSS signals.

\section{A. Correlator outputs in presence of bit transition}

Without loss of generality, it is possible to consider that the correlation is performed between 0 and $T_{I}$. Let us assume that a bit sign transition occurs at $t_{0}$ where $0 \leq t_{0} \leq T_{I}$. As presented in [11], the correlator outputs expressions can be shown to be equal:

$$
\begin{gathered}
I_{t_{0}, x}(k)=\left[\begin{array}{c}
n_{I_{t_{0}, x}}(k)+\frac{A_{x}}{2} R_{x}\left(\varepsilon_{\tau}\right) \times \\
-\sin \left(\pi \varepsilon_{f} T_{I}+\varepsilon_{\phi_{0}}\right) \times \frac{\cos \left(\pi \varepsilon_{f} T_{I}\right)}{2 \pi \varepsilon_{f} T_{I}} \\
+\frac{\sin \left(2 \pi \varepsilon_{f} t_{0}+\varepsilon_{\phi_{0}}\right)}{2 \pi \varepsilon_{f} T_{I}}
\end{array}\right] \\
Q_{t_{0}, x}(k)=\left[\begin{array}{c}
n_{Q_{t_{0}, x}}(k)+\frac{A_{x}}{2} R_{x}\left(\varepsilon_{\tau}\right) \times \\
-\cos \left(\pi \varepsilon_{f} T_{I}+\varepsilon_{\phi_{0}}\right) \times \frac{\cos \left(\pi \varepsilon_{f} T_{I}\right)}{2 \pi \varepsilon_{f} T_{I}} \\
+\frac{\cos \left(2 \pi \varepsilon_{f} t_{0}+\varepsilon_{\phi_{0}}\right)}{2 \pi \varepsilon_{f} T_{I}}
\end{array}\right]
\end{gathered}
$$

\section{B. Acquisiton process in presence of data}

The acquisition detector, as the sum of the correlator outputs, will be affected by the presence of data sign transitions. Considering bit sign transition, the non-centrality parameter depending on (12) becomes dependent on the parameter (16) in function of the sign transition location expressed for one summation:

$$
\begin{gathered}
\lambda_{1, t_{0}, x}=\left(E\left[\frac{I_{t_{0}, x}(k)}{\sigma^{2}}\right]\right)^{2}+\left(E\left[\frac{Q_{t_{0}, x}(k)}{\sigma^{2}}\right]\right)^{2} \\
=\frac{A_{x}^{2}}{N_{0}} T_{I} R_{x}^{2}\left(\varepsilon_{\tau}\right) \times \\
\frac{\cos ^{2}\left(\pi \varepsilon_{f} T_{I}\right)+1-2 \cos \left(\pi \varepsilon_{f} T_{I}\right) \cos \left(\pi \varepsilon_{f}\left(T_{I}-2 t_{0}\right)\right)}{\left(\pi \varepsilon_{f} T_{I}\right)^{2}}
\end{gathered}
$$

[11] provides a study on the non-centrality parameter and its dependence with the sign transition location $t_{0}$, the Doppler frequency error ([10] has presented initial results and [11] brings a further investigation). Considering no Doppler and code delay errors, the first intuitive result is that the losses due to a bit sign transition can be important for a bit sign transition close to the center of the coherent integration interval as represented in Fig. 8. This induces potential strong degradation with respect to the probability of detection assessed without considering bit transitions. 


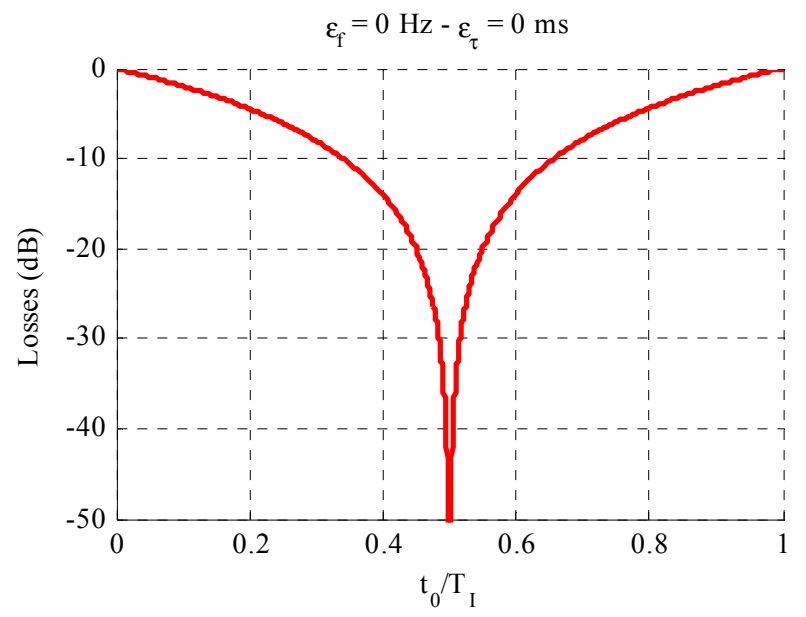

Fig. 8: Losses on the non-centrality parameter due to a bit sign transition

The mathematical development of the non-centrality parameter permits to give it when the Doppler frequency error is null. It is:

$$
\lambda_{1, t_{0}, x}=\frac{A_{x}^{2}}{N_{0}} T_{I} R_{x}^{2}\left(\varepsilon_{\tau}\right)\left(1+4 \frac{t_{0}^{2}}{T_{I}^{2}}-\frac{4 t_{0}}{T_{I}}\right)
$$

\section{Probabilities of detection considering bit sign transitions}

The average probability of detection depends on the bit sign transition location and on the number of bit sign occurring during the computation of the acquisition detector. It can be computed using:

$$
P_{D, t_{0}}=\sum_{n=0}^{N} P_{n} \times P_{D_{n}}
$$

Where

- $\quad N$ is the number of bit sign transitions, it depends on the acquisition technique (on one or two components) and on the number of non-coherent summations

- $\quad P_{D, t_{0}}$ is the average probability of detection considering a uniform distribution of the bit sign transition location

- $P_{D_{n}}$ is the probability of detection if $n$ bit sign transitions occur for $n$ between 0 and $N$

- $P_{n}$ is the probability of occurrence of $n$ bit sign transitions with $\sum_{n=0}^{N} P_{n}=1$.

Let us go further by providing the theoretic probability of detection for each considered GNSS signal.

\section{1) Acquisition based on one component}

\section{a) Data/Pilot GNSS signals}

In the case of the acquisition on one component and for the dwell time of $K \times T_{I}$ ms where $T_{I}$ is the coherent integration time (assumed equal to the spreading code period) and $K$ the number of non-coherent summations, the maximum number of bit sign transitions $N$ is the number of non-coherent summations, which means $N=K$.
At each spreading code period, a bit sign transition occurs with a probability of $p_{x}$. The number of bit sign transitions can thus be modeled as a binomial distribution $\mathcal{B}\left(K, p_{x}\right)$. Then, the probability that $n$ bit sign transitions occurs is:

$$
\begin{aligned}
P_{n} & =\left(\begin{array}{c}
K \\
n
\end{array}\right) p_{x}^{n}\left(1-p_{x}\right)^{K-n} \\
P_{D_{n}} & =1-\mathcal{F}_{\chi^{2}\left(2 K, \lambda_{n, t_{0}, x}\right)}\left(T_{h}\right)
\end{aligned}
$$

The non-centrality parameter $\lambda_{n, t_{0}, x}$ corresponds:

$$
\lambda_{n, t_{0}, x}=n \times \lambda_{1, t_{0}, x}+(K-n) \times \lambda_{0,0, x}
$$

\section{b) GPSL1 C/A}

The case of GPS L1 C/A is particular because the spreading code period is shorter than the data bit duration. As explained in [11] and illustrated by Fig. 9, over 20 successive 1-ms correlations, only one can be affected by a data bit transition which can involve a bit sign transition. The 19 other 1-ms correlations will be free of bit transition.

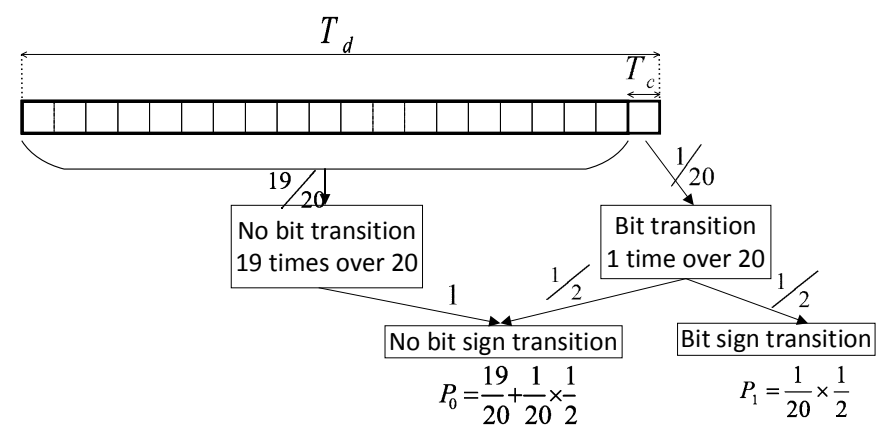

Fig. 9: Scheme to determine the probability of detection (GPS L1 C/A)

The probability of detection can be generalized for any $K \times T_{I}$, the maximum number of bit transitions being $N=$ $\left\lceil\frac{K \times T_{I}}{T_{d}}\right\rceil$. For a given $K \times T_{I}$, according to the bit sign transition location, there can be $N-1$ or $N$ bit sign transitions. Indeed, for example, for $K \times T_{I}=35 \mathrm{~ms}$, in $25 \%$ of the cases, 1 bit sign transition occurs and in $75 \%$ of the cases, 2 bit sign transitions occur. This percentage of $N-1$ bit transitions denoted $\alpha$ is:

$$
\alpha=N-\frac{K \times T_{I}}{T_{d}}=\left\{\frac{K \times T_{I}}{T_{d}}\right\}
$$

The probability of detection results in 2 sums:

$$
\begin{aligned}
& P_{D, t_{0}}=\frac{\alpha}{2^{N-1}} \sum_{n=0}^{N-1}\left(\begin{array}{c}
N-1 \\
n
\end{array}\right) P_{D_{n}}+\frac{1-\alpha}{2^{N}} \sum_{n=0}^{N}\left(\begin{array}{l}
N \\
n
\end{array}\right) P_{D_{n}} \\
= & \sum_{n=0}^{N-1}\left(\frac{\alpha}{2^{N-1}}\left(\begin{array}{c}
N-1 \\
n
\end{array}\right)+\frac{1-\alpha}{2^{N}}\left(\begin{array}{l}
N \\
n
\end{array}\right)\right) P_{D_{n}}+\frac{1-\{N\}}{2^{N}} P_{D_{N}}
\end{aligned}
$$

\section{2) Acquisition based on both components}

In the case of an acquisition technique based on both data and pilot components and using dwell time of $K T_{I}$, the maximum number of bit sign transitions is $N=2 K$ ( $K$ bit sign transitions per component). For instance, if $K=5$, there can be $n=0, \ldots, 10$ bit sign transitions. In Fig. 10, the probabilities of 
occurrence of $n$ bit sign transitions are given for the data/pilot signals. As it can be observed, they are the same for Galileo E1 OS and GPS L1C $\left(p_{d}=\overline{p_{d}}=p_{p}=\overline{p_{p}}\right)$ but not for the GPS L5 signal $\left(p_{d} \neq \overline{p_{d}}\right)$.

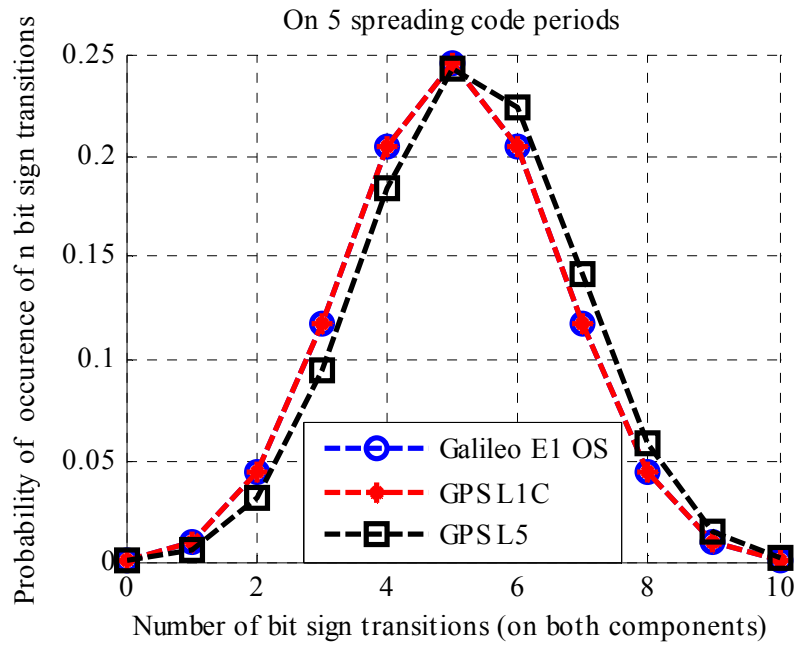

Fig. 10: Probability of occurrence of $n$ bit sign transitions

\section{a) Galileo E1 OS signal}

For the Galileo E1 OS signal, the probability of a bit sign transition on each component is one half, then the number of bit sign transitions on $K$ spreading code periods is a binomial distribution $\mathcal{B}\left(2 K, \frac{1}{2}\right)$. Because the total signal power is split in $50 \%$ on each component, $\lambda_{0, d}=\lambda_{0, p}$ and $\lambda_{t_{0}, d}=\lambda_{t_{0}, p}$ and then the probability of detection depends on:

$$
\begin{aligned}
P_{n} & =\quad \frac{1}{2^{2 K}}\left(\begin{array}{c}
2 K \\
n
\end{array}\right) \\
P_{D_{n}} & =1-\mathcal{F}_{\chi^{2}\left(4 K, \lambda_{n, t_{0}}\right)}\left(T_{h}\right) \\
\text { Where } \lambda_{n, t_{0}} & =n \times \lambda_{1, t_{0}, x}+(2 K-n) \times \lambda_{0,0, x}
\end{aligned}
$$

\section{b) GPS L5 signal}

For the GPS L5 signal, as previously seen, the probability of bit sign transitions on the data component is not $1 / 2\left(p_{d}=\right.$ $0.55)$ as for the Galileo E1 OS signal. The number of bit sign transitions on the data component should thus be considered, let us denote it $n_{d}$. In the same way, $n_{p}$ the number on bit sign transitions on the pilot component can be defined but it is $n_{p}=n-n_{d}$.

Over $K$ spreading code periods, $n_{d}$ is upper bounded by $\min (K, n)$, there cannot be more bit sign transitions on the data component than the total number of bit sign transitions or the number of non-coherent summations. Furthermore, the number of data bit sign transitions on the data component should satisfy $n_{d} \geq \max (n-K, 0)$ because for example if $n=2 K$ (maximum number of bit sign transitions), this implies that on each component, $K$ bit sign transitions occurs and then $n_{d}=$ $K$.
Then the probability of occurrence of $n$ bit sign transitions is:

$$
\begin{array}{ccc}
P_{n, n_{d}}= & \left(\begin{array}{c}
K \\
n_{d}
\end{array}\right)\left(\begin{array}{c}
K \\
n-n_{d}
\end{array}\right) \times \\
P_{D_{n, n_{d}}}= & \begin{array}{c}
p_{d}^{n_{d}}\left(1-p_{d}\right)^{K-n_{d}} p_{p}^{n-n_{d}}\left(1-p_{p}\right)^{K-n+n_{d}} \\
1-\mathcal{F}_{\chi^{2}\left(4 K, \lambda_{n, t_{0}}\right)}\left(T_{h}\right)
\end{array} \\
\text { Where } \lambda_{n, t_{0}}= & n \times \lambda_{1, t_{0}, x}+(2 K-n) \times \lambda_{0,0, x}
\end{array}
$$

Then the probability of detection (18) becomes:

$$
P_{D, t_{0}}=\sum_{n=0}^{N} \sum_{n_{d}=\max (n-K, 0)}^{\min (K, n)} P_{n, n_{d}} \times P_{D_{n, n_{d}}}
$$

\section{c) GPS L1C signal}

The GPS L1C signal is characterized by a difference in power on both components. This implies a non-centrality parameter per component: $\lambda_{0,0, d} \neq \lambda_{0,0, p}$ and $\lambda_{1, t_{0}, d} \neq \lambda_{1, t_{0}, p}$. The non-centrality parameter contains:

- $\quad K$ terms from the data component $\left(n_{d}\right.$ considering bit sign transition and $K-n_{d}$ without bit transition)

- $\quad K$ terms from the pilot component (there are $n-n_{d}$ bit sign transitions and $K-\left(n-n_{d}\right)$ correlations without bit transition):

$$
\begin{gathered}
n_{d} \lambda_{1, t_{0}, d}+\left(K-n_{d}\right) \lambda_{0,0, d} \\
+\left(n-n_{d}\right) \lambda_{1, t_{0}, p}+\left(K-n+n_{d}\right) \lambda_{0,0, p}
\end{gathered}
$$

Because the probability of bit sign transitions on each component is assumed to be one half, the probability of occurrence given in (24) can be simplified:

$$
\begin{aligned}
P_{n, n_{d}} & =\frac{1}{2^{2 K}}\left(\begin{array}{c}
K \\
n_{d}
\end{array}\right)\left(\begin{array}{c}
K \\
n-n_{d}
\end{array}\right) \\
P_{D_{n, d}} & =1-\mathcal{F}_{\chi^{2}\left(4 K, \lambda_{n / n_{d}, t_{0}}\right)}\left(T_{h}\right)
\end{aligned}
$$

\section{Simulations Results}

This work focuses only on the impact of bit sign transitions on the acquisition performance through the study of the probability of detection. In this context, for simulation, the incoming code delay $\tau$ and the Doppler frequency $f_{d}$ are assumed to be perfectly estimated. Moreover, the coherent integration time is chosen to be:

- An integer divider of the data bit duration and multiple of the spreading code period for GPS L1 C/A. As illustrated in Fig. 9, the dwell time is processed in blocks of $20 \mathrm{~ms}$ to respect the data bit duration.

- The spreading code period which is the bit duration for data/pilot signals

It seems to be clear that if a bit transition occurs at $t_{0}$ with $t_{0}$ in $\left[0, T_{I}\right]$, the next bit transition occurs at $t_{0}+T_{d}\left(t_{0}+T_{I}\right.$ for data/pilot signals). Furthermore, the bit sign transition location is supposed to follow a uniform distribution on $\left[0, T_{I}\right]$. 


\section{A. GPS L1 C/A signal}

\section{1) General result on the probability of detection}

The challenge for the GPS L1 C/A signal is to determine the optimal coherent integration time. Indeed, because the data bit duration is twenty times longer than the spreading code period, the coherent integration time could be whichever integer divider of the data bit duration. Without considering bit sign transition, it is preferable to choose long coherent integration time [13]; then for example for a dwell time $K T_{I}$ of $20 \mathrm{~ms}$, the best combination to have the high probability of detection is to set $T_{I}$ to $20 \mathrm{~ms}$ and $K$ to 1 . As illustrated in Fig. 11 for a null frequency Doppler frequency error, the higher the coherent integration time, the higher the probability of detection is

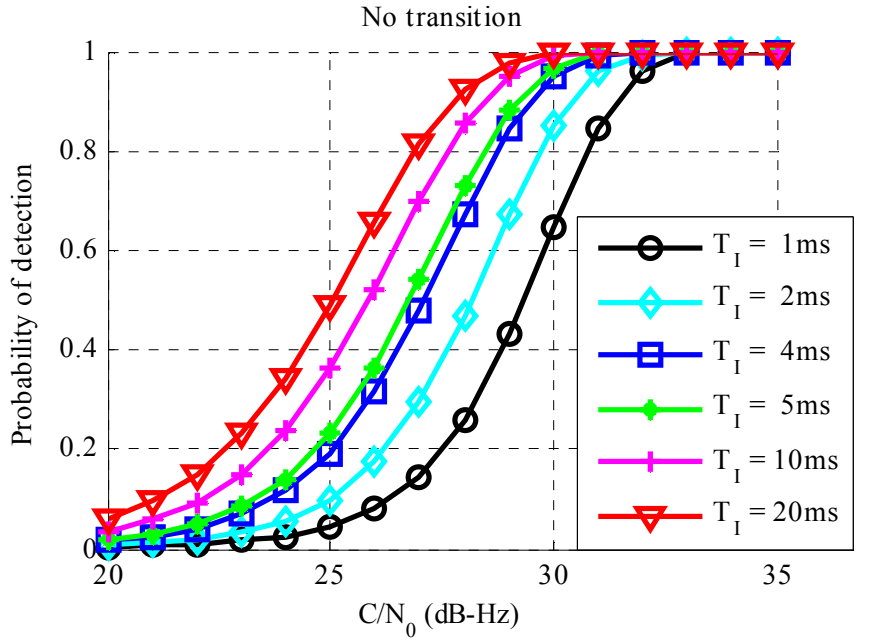

Fig. 11: Probability of detection for $K T_{I}=20 \mathrm{~ms}$ without bit sign transition (GPS L1 C/A)

Fig. 12 and Fig. 13 give the probabilities of detection for a total integration time of $20 \mathrm{~ms}$ for the 6 values of integration time (integer divider of $20 \mathrm{~ms}$ ) for two bit sign transition locations: at a quarter and in the middle of the coherent integration time.

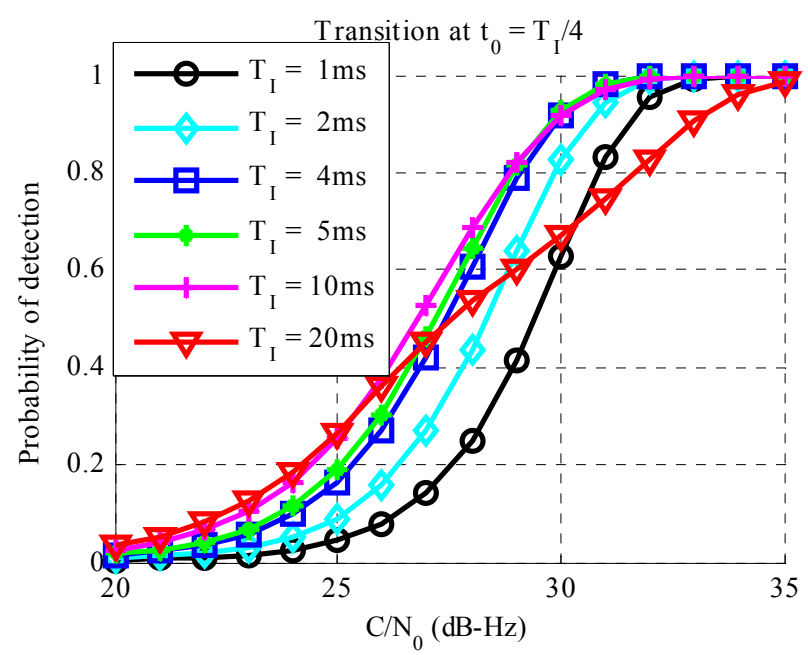

Fig. 12: Probability of detection for $K T_{I}=\mathrm{ms}$ and 1 bit sign transition at $t_{0}=T_{I} / 4($ GPS L1 C/A)
For a coherent integration time of $1 \mathrm{~ms}$ (black circle curve), there is a slight degradation on the probability of detection wherever is the bit sign transition. The most affected probability of detection is for a coherent integration time of 20 $\mathrm{ms}$ (red triangle curve). In the worst case (transition at $10 \mathrm{~ms}$ ), even for high $\mathrm{C} / \mathrm{N}_{0}$, the probability of detection stagnates at 0.5 . This can be explained by the theoretical formula (22): there is a probability of one half that there is a bit sign transition and if it is the case, the probability is 0 , if not, the probability is 1 .

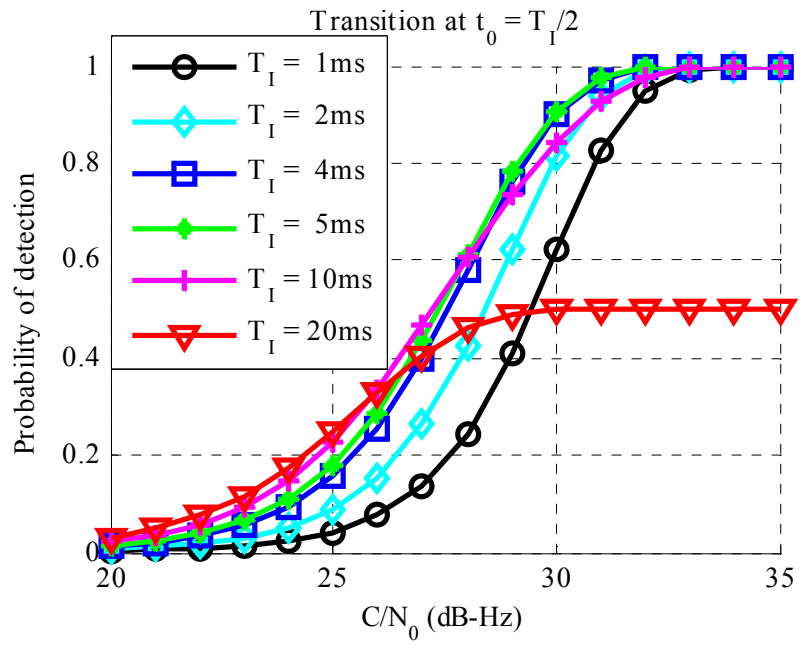

Fig. 13: Probability of detection for $K T_{I}=20 \mathrm{~ms}$ and 1 bit sign transition at $t_{0}=T_{I} / 2(\mathrm{GPS} \mathrm{L1} \mathrm{C} / \mathrm{A})$

Table II and Table III give the probability of detection for the optimal coherent integration time between $\{1,2,4,5,10,20\} \mathrm{ms}$ depending on the bit sign transition location and the $\mathrm{C} / \mathrm{N}_{0}$. For $\mathrm{C} / \mathrm{N}_{0}$ values higher than $31 \mathrm{~dB}-\mathrm{Hz}$, the probability of detection is 1 . As presented in Fig. 12 and Fig. 13, for $\mathrm{C} / \mathrm{N}_{0}$ between $27 \mathrm{~dB}-\mathrm{Hz}$ and $35 \mathrm{~dB}-\mathrm{Hz}$, the optimal choice for the coherent integration time is 4 or $5 \mathrm{~ms}$. For higher $\mathrm{C} / \mathrm{N}_{0}$, the signal is strong enough to be acquired with short coherent integration times because for a high coherent time, the probability of detection is highly affected. At the contrary, for lower $\mathrm{C} / \mathrm{N}_{0}$, long coherent integration times are required to accumulate signal power.

TABLE II. PROBABILITY OF DETECTION FOR THE OPTIMAL INTEGRATION TIME

\begin{tabular}{|c|c|c|c|c|c|c|c|c|c|c|}
\hline & \multicolumn{9}{|c|}{ Bit sign transition location $t_{0}=\frac{a}{b} T_{I}$} \\
\hline & & & 1 & 1 & 3 & 1 & 5 & 3 & 7 & 1 \\
\hline & & $\bar{b}=0$ & $\overline{16}$ & $\overline{8}$ & $\overline{16}$ & $\overline{4}$ & $\overline{16}$ & $\overline{8}$ & $\overline{16}$ & $\overline{2}$ \\
\hline \multirow{4}{*}{ 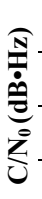 } & $n$ & 0.49 & 0.41 & 0.34 & 0.29 & 0.27 & 0.25 & 0.25 & 0.25 & 0.25 \\
\hline & $\hat{\nu}$ & 0.81 & 0.72 & 0.61 & 0.56 & 0.53 & 0.50 & 0.48 & 0.47 & 0.47 \\
\hline & શे & 0.98 & 0.94 & 0.90 & 0.86 & 0.82 & 0.80 & 0.79 & 0.78 & 0.78 \\
\hline & $y$ & 1 & 1 & 0.99 & 0.99 & 0.98 & 0.98 & 0.98 & 0.97 & 0.97 \\
\hline
\end{tabular}


TABLE III. OPTIMAL COHERENT INTEGRATION TIME $T_{I}\left(\right.$ IN MS) FOR $K T_{I}=20$ MS (GPS L1 C/A)

\begin{tabular}{|c|c|c|c|c|c|c|c|c|c|c|}
\hline & \multicolumn{9}{|c|}{ Bit sign transition location $t_{0}=\frac{a}{b} T_{I}$} \\
\hline & & $\underline{a}-0$ & 1 & 1 & 3 & 1 & 5 & 3 & 7 & 1 \\
\hline & & $\bar{b}=\mathbf{0}$ & $\overline{16}$ & $\overline{8}$ & $\overline{16}$ & $\overline{4}$ & $\overline{16}$ & 8 & $\overline{16}$ & $\overline{2}$ \\
\hline \multirow{8}{*}{ 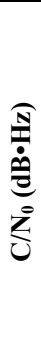 } & 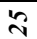 & 20 & 20 & 20 & 20 & 20 & 20 & 20 & 20 & 20 \\
\hline & $\hat{v}$ & 20 & 20 & 20 & 10 & 10 & 10 & 10 & 10 & 10 \\
\hline & নิ & 20 & 20 & 10 & 10 & 10 & 5 & 5 & 5 & 5 \\
\hline & $\bar{m}$ & 20 & 10 & 10 & 10 & 5 & 5 & 5 & 5 & 5 \\
\hline & $\tilde{m}$ & 20 & 10 & 10 & 5 & 5 & 5 & 4 & 4 & 4 \\
\hline & $\hat{m}$ & 20 & 10 & 5 & 5 & 5 & 4 & 4 & 4 & 4 \\
\hline & $\hat{\text { ⿵े }}$ & 2 & 2 & 4 & 4 & 4 & 4 & 4 & 4 & 4 \\
\hline & ले & 1 & 1 & 1 & 1 & 1 & 1 & 1 & 1 & 1 \\
\hline
\end{tabular}

For low $\mathrm{C} / \mathrm{N}_{0}$, the same study was done and presented in Table IV but for a total integration time $K T_{I}$ of $100 \mathrm{~ms}$. In this case, the probability of detection is close to 1 (the minimum is 0.92 for $25 \mathrm{~dB}-\mathrm{Hz}$ and a bit sign transition at $5 \mathrm{~ms}$ ). When the bit sign transition location gets close to the middle of the coherent integration time, the optimal choice for the coherent integration time is still 4 or $5 \mathrm{~ms}$.

TABLE IV. OPTIMAL COHERENT INTEGRATION TIME $T_{I}$ (IN MS) FOR $K T_{I}=100$ MS (GPS L1 C/A)

\begin{tabular}{|c|c|c|c|c|c|c|c|c|c|c|}
\hline & \multicolumn{9}{|c|}{ Bit sign transition location $t_{0}=\frac{a}{b} T_{I}$} \\
\hline & & & 1 & 1 & 3 & 1 & 5 & 3 & 7 & 1 \\
\hline & & $\bar{b}=0$ & $\overline{16}$ & $\overline{8}$ & $\overline{16}$ & $\overline{4}$ & $\overline{16}$ & $\overline{8}$ & $\overline{16}$ & $\overline{2}$ \\
\hline \multirow{4}{*}{ 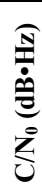 } & $\approx$ & 20 & 20 & 20 & 10 & 10 & 10 & 10 & 10 & 10 \\
\hline & $\hat{v}$ & 20 & 20 & 10 & 10 & 10 & 10 & 5 & 5 & 5 \\
\hline & શิ & 20 & 20 & 10 & 10 & 5 & 5 & 5 & 5 & 5 \\
\hline & mे & 4 & 4 & 4 & 5 & 5 & 5 & 5 & 4 & 4 \\
\hline
\end{tabular}

\section{2) Average probability of detection}

To conclude this section on the GPS L1 C/A signal, the average probability of detection on the bit sign transition location is given. For each coherent integration time, the probability of detection is computed for 51 different bit sign transition locations uniformly distributed between 0 and $T_{I} / 2$ and then the average value over the 51 obtained probabilities of detection is taken. Fig. 14 presents the result for a total integration time of $20 \mathrm{~ms}$. As it can be observed, too short coherent integration times ( 1 or $2 \mathrm{~ms}$ ) are not the best choices when considering bit sign transition. For very low $\mathrm{C} / \mathrm{N}_{0}$, as previously said, the longer the coherent integration time is, the best is. For $\mathrm{C} / \mathrm{N}_{0}$ between $25 \mathrm{~dB}-\mathrm{Hz}$ and $28 \mathrm{~dB}-\mathrm{Hz}$, the probabilities of detection for a coherent integration time between $4 \mathrm{~ms}$ and $20 \mathrm{~ms}$ are very close (at maximum difference of $1 \mathrm{~dB})$. After $28 \mathrm{~dB} \cdot \mathrm{Hz}$, the red curve $\left(T_{I}=\right.$ $20 \mathrm{~ms}$ ) falls compared with the other curves and the best choices for the coherent integration time is 4,5 and $10 \mathrm{~ms}$.

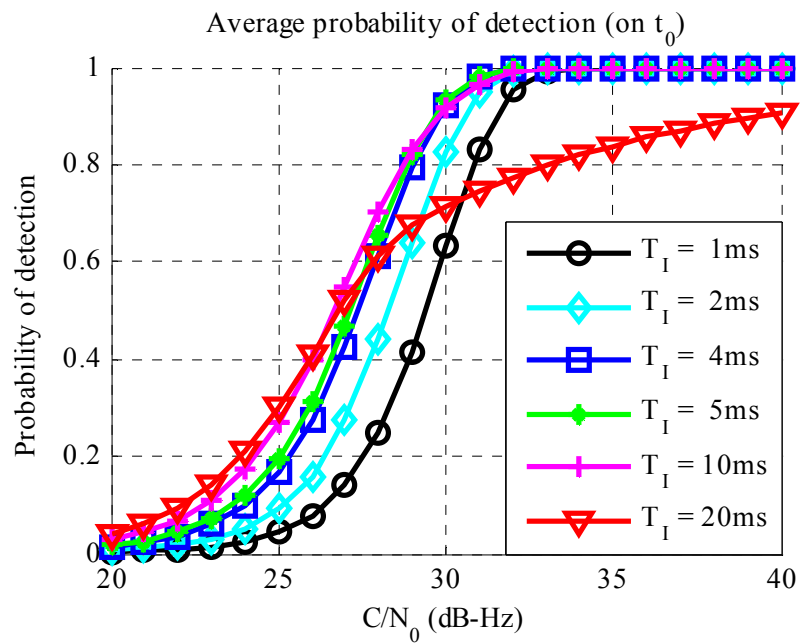

Fig. 14: Average probability of detection (on the bit sign transition location) for a $K T_{I}=20 \mathrm{~ms}$ (GPS L1 C/A)

For a probability of detection $P_{D}$ of 0.95 , there is a loss of 2 $\mathrm{dB}$ due to bit transition for optimal coherent integration times. Indeed, without data modulation, the probability of detection is reached for a $\mathrm{C} / \mathrm{N}_{0}$ above $28.4 \mathrm{~dB}-\mathrm{Hz}(20 \mathrm{~ms})$ whereas a $\mathrm{C} / \mathrm{N}_{0}$ of $30.3 \mathrm{~dB}-\mathrm{Hz}$ is required when the bit sign transition is considered and for a coherent integration time of $5 \mathrm{~ms}$. Let us note that in the case of no data modulation (Fig. 11), there is only a loss of $0.4 \mathrm{~dB}$ for the same desired probability of detection and a coherent integration time $(5 \mathrm{~ms})$.

\section{B. Galileo E1 OS signal}

\section{1) General result on the probability of detection}

For a coherent integration of $T_{I}=4 \mathrm{~ms}$, there can be 0 or 1 bit sign transition on each component. In each case (no bit transition, 1 on one of both components or 1 on both components), the associated probability of detection is represented in the left part of Fig. 15. For one bit sign transition on both components at $t_{0}=\frac{T_{I}}{2}$, the probability of detection is null (blue curve). Indeed, the non-centrality parameter is null (17) but this case occurs only one time over 4 which explains the average probability (magenta curve) at 0.75 for high $\mathrm{C} / \mathrm{N}_{0}$.
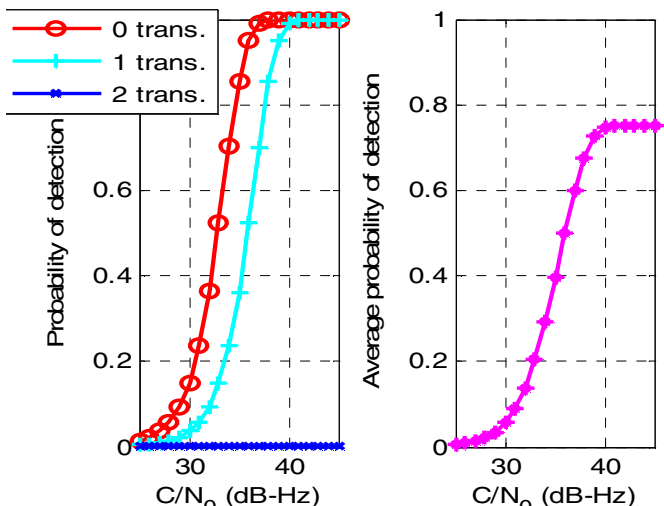

Fig. 15: Probabilities of detection for 0,1 or 2 transitions during the first spreading code period on both components in the middle of the integration interval (Galileo E1 OS) 
2) Probability of detection in the worst case location for data sign transition

Fig. 16 presents the probabilities of detection for both acquisition techniques: on one component (data or pilot) and on both components on one spreading code period. Two curves (blue and red curves) correspond to the probabilities without considering bit sign transition. The acquisition on both components provides better probabilities of detection than acquisition on one component. The result stays true when a bit sign transition occurs in the middle of the integration interval that means at $2 \mathrm{~ms}$ (magenta and cyan curves). As it was the case for GPS L1 C/A and a coherent integration time equal to the data bit duration $\left(T_{I}=20 \mathrm{~ms}\right)$, for high $\mathrm{C} / \mathrm{N}_{0}$, the probability of detection is equal to 0.5 for the acquisition on one component (square cyan curve).

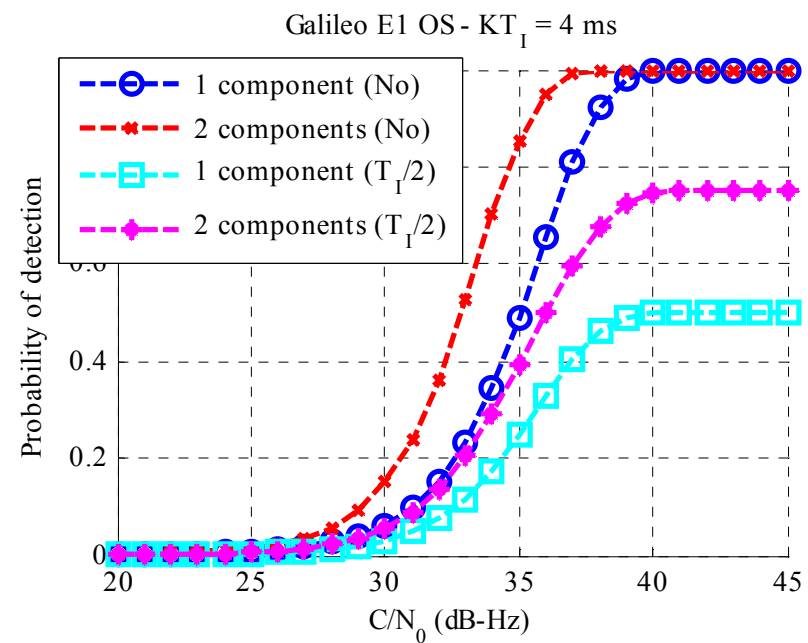

Fig. 16: Probabilities of detection on $4 \mathrm{~ms}$ for acquisition on one or two components (Galileo E1 OS)

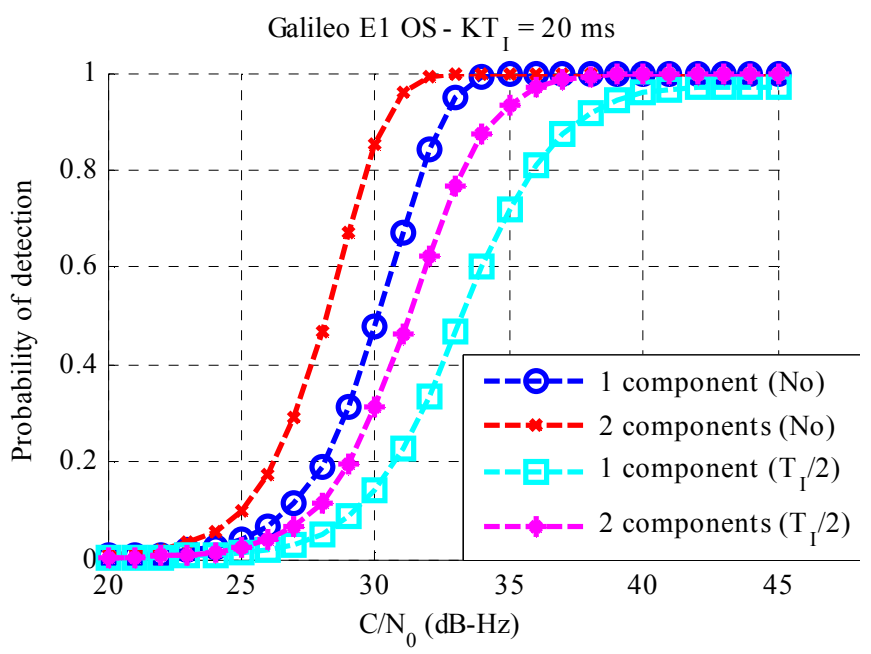

Fig. 17: Probabilities of detection on $20 \mathrm{~ms}$ for acquisition on one or two components for a bit sign transition in the middle of the coherent integration time (Galileo E1 OS)

As illustrated in Fig. 16 for $K=1$ and Fig. 17, for $K=5$ non-coherent summations, the probability of detection is still higher for acquisition on both components. Here, the probabilities of detection are given for the worst case that means a bit sign transition in the middle of the coherent integration time but the result is true whichever the bit sign transition location.

\section{3) Average probability of detection}

The average probability of detection on the bit sign transition location is computed for both acquisition techniques and presented in Fig. 18. Obviously, the higher probability of detection is for the acquisition on both components. We can remark that the losses between the two curves are around $2 \mathrm{~dB}$ which means that is less than in the case of no data modulation (Fig. 16). For a given probability of detection of 0.95 and a total integration time of $20 \mathrm{~ms}$, if $31 \mathrm{~dB}-\mathrm{Hz}$ is required to acquire Galileo E1 OS on both components, then:

- The received $\mathrm{C} / \mathrm{N}_{0}$ should be $3 \mathrm{~dB}$ higher in order to acquire the signal with bit sign transitions

- If only one component is used, when not considering bit sign transition, $2 \mathrm{~dB}$ more are required. When considering bit sign transitions, $4 \mathrm{~dB}$ more are needed to reach the same probability of detection.

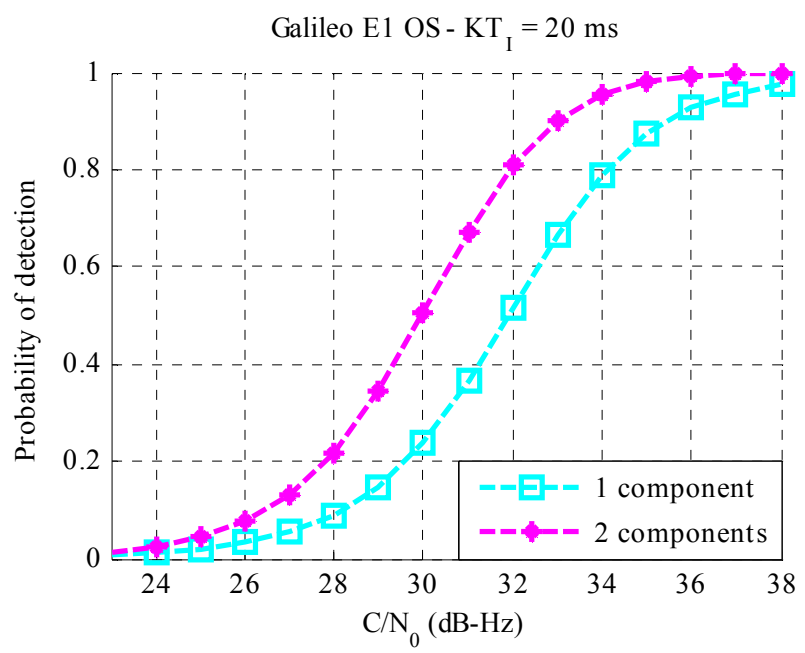

Fig. 18: Average probabilities of detection on $t_{0}$ for a total integration time of $20 \mathrm{~ms}$ (Galileo E1 OS)

\section{GPS L5 signal}

\section{1) General result on the probability of detection}

For the GPS L5 signal, the coherent integration time is 1 ms, that means the spreading code period. Compared to Galileo E1 OS, the probabilities of detection are lower because the integration time is shorter. The other difference with Galileo E1 OS is that the probability of a bit sign transition on the data component is not $0.5\left(p_{d}=0.55\right)$, then this implies different values of probabilities of occurrence when only one component is acquired depending if it is the data or the pilot component (square cyan curve for the pilot component, green for the data component). 
2) Probability of detection in the worst case location for data sign transition

As it can be observed in Fig. 19, once again, for one spreading code period and bit sign transitions at $0.5 \mathrm{~ms}$ (middle of the coherent integration time), the probability of detection for one component is around 0.5 (for the data component, it is $\left.1-p_{d}=0.45\right)$.

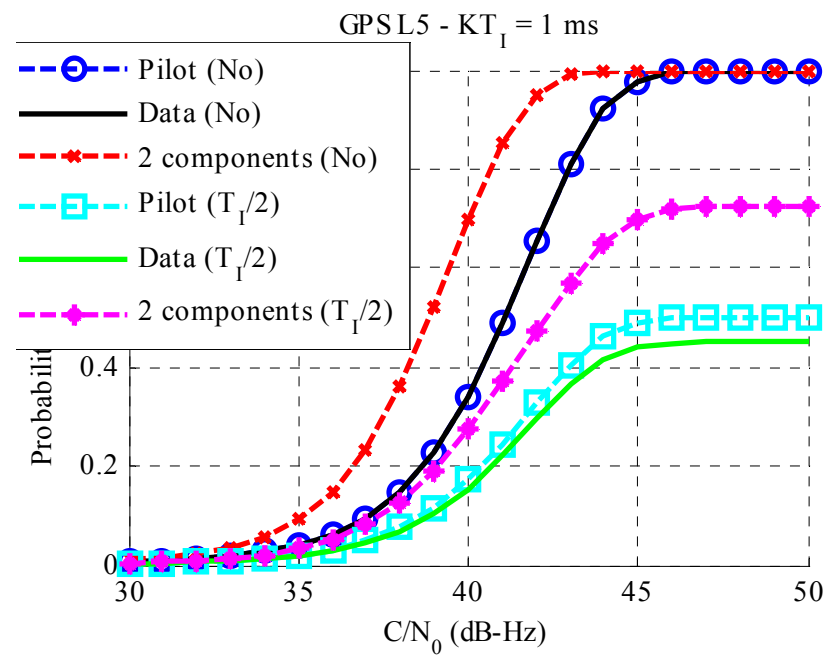

Fig. 19: Probabilities of detection on $1 \mathrm{~ms}$ (spreading code period) for acquisition in one or two components (GPS L5)

For a dwell time of $K \times T_{I}=20 \mathrm{~ms}$, when bit sign transitions occur at $0.5+k T_{I}$ for $k$ from 0 to $20-1$, the probability of detection presents a loss higher than $3 \mathrm{~dB}$ (when not considering bit sign transitions). The losses seem to be lower than for Galileo E1 OS but the probabilities of detection are higher for Galileo E1 OS which can be explained by a longer coherent integration time (smaller impact due to bit transition but correlator outputs more noisy).

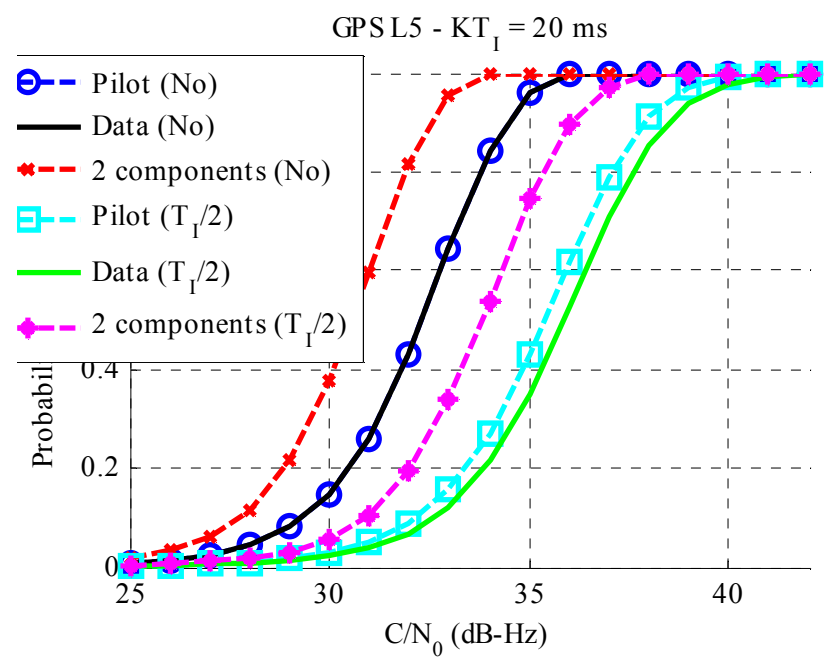

Fig. 20: Probabilities of detection on $20 \mathrm{~ms}$ for acquisition in one or two components for a bit sign transition in the middle of the coherent integration time (GPS L5)

\section{3) Average probability of detection}

Due to the short coherent integration time, the average probability of detection (Fig. 21) for acquisition on both components is close to the probability of detection in the worst case (transition in the middle of the coherent integration time) in particular for high $\mathrm{C} / \mathrm{N}_{0}$. Once again, it seems to be really preferable to acquire both components to limit the losses on the probabilities of detection due to bit sign transitions.

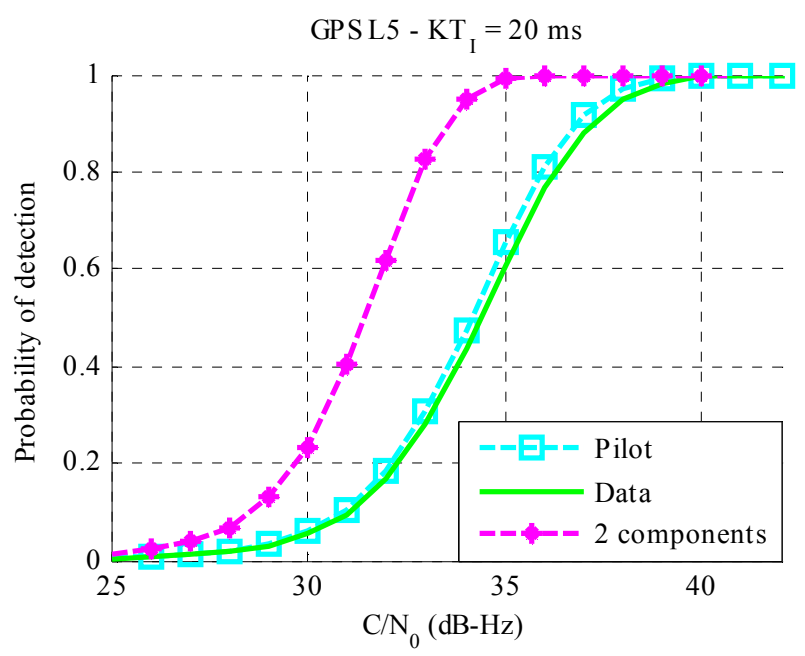

Fig. 21: Average probabilities of detection on $t_{0}$ for a total integration time of 20 ms (GPS L5)

\section{GPS L1C signal}

For the GPS L1C signal, 75\% of the signal power is concentrated on the pilot component, then the difference between the acquisition on both components or only on the pilot component can be anticipated as very small.

1) Probability of detection in the worst case location for data sign transition

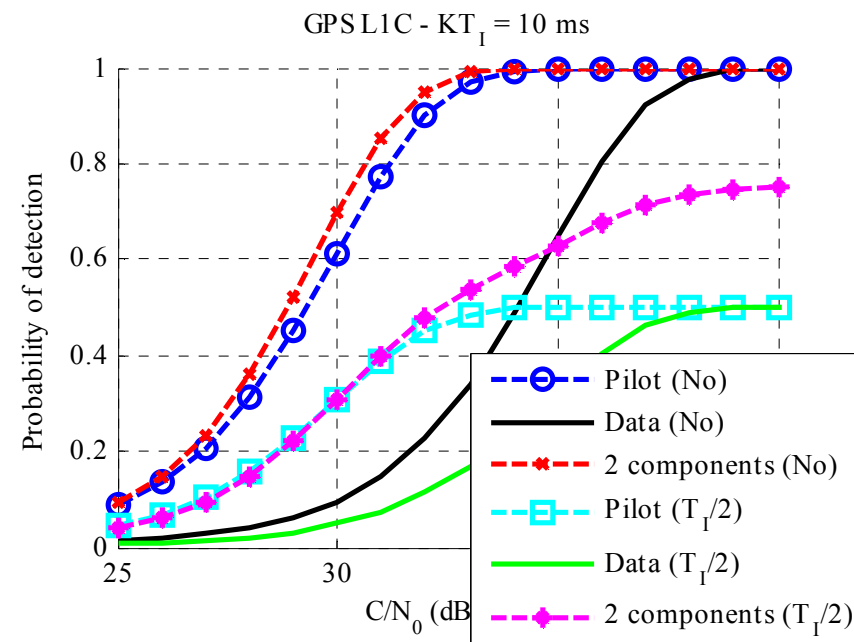

Fig. 22: Probabilities of detection on $20 \mathrm{~ms}$ for acquisition in one or two components for a bit sign transition in the middle of the coherent integration time (GPS L1C)

As presented in Fig. 22 and Fig. 23, when modulation by a binary sequence is not considered both curves (acquisition of 
pilot or both components) are very close (red and blue circle curves). The difference between the probabilities of detection for an acquisition on the data component or on the pilot component is high due to the difference in signal power.

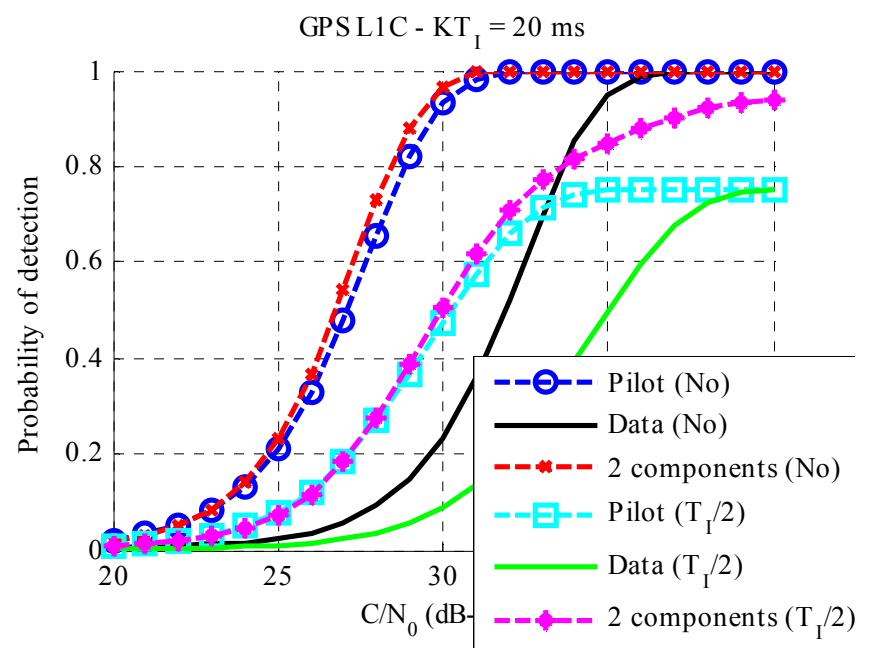

Fig. 23: Probabilities of detection on $20 \mathrm{~ms}$ for acquisition in one or two components for a bit sign transition in the middle of the coherent integration time (GPS L1C)

Considering bit sign transitions, for low $\mathrm{C} / \mathrm{N}_{0}$, the probabilities of detection for acquisition on both components or on pilot component match. For high $\mathrm{C} / \mathrm{N}_{0}$, the difference tends to blur when the total integration time increases. As presented for Galileo E1 OS in Fig. 15, the probability of occurrence that the maximum number of bit sign transitions occurs becomes lower when the number of non-coherent summations increases and then the associated probability of detection (which has a null value) has a lower impact on the average probability of detection.

\section{2) Average probability of detection}

This trend is confirmed by Fig. 24 where the difference between the two curves is very low. A loss of $5 \mathrm{~dB}$ on the probability of detection when considering or not bit sign transitions is observed.

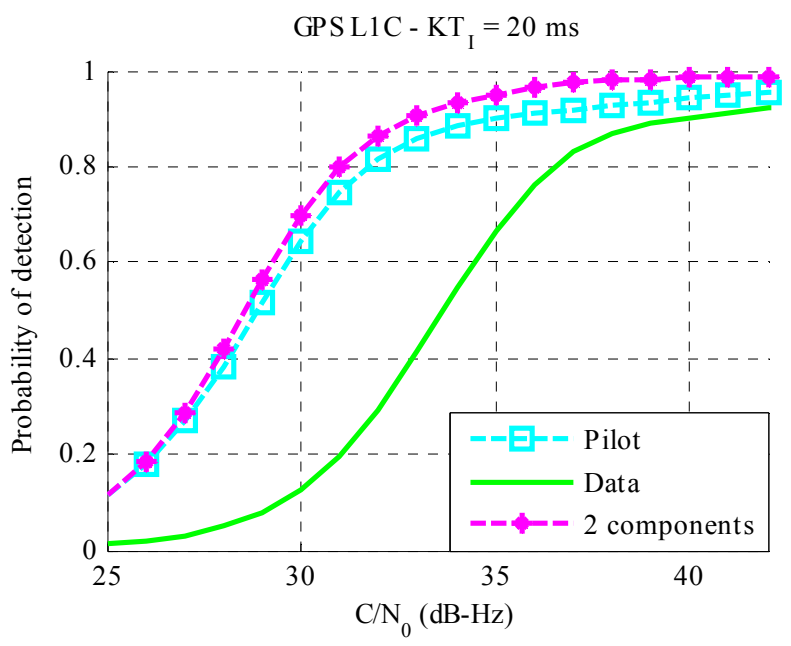

Fig. 24: Average probabilities of detection on $t_{0}$ for a total integration time of 20 ms (GPS L1C)

\section{E. Discussion}

Table V and Table VI conclude this section by presenting the simulation results. In order to compare the performance of the 4 considered GNSS signals, the average probability of detection on the bit sign transition location is given for each signal and for a dwell time of $20 \mathrm{~ms}$ and for 3 values of $\mathrm{C} / \mathrm{N}_{0}$. At $27 \mathrm{~dB}-\mathrm{Hz}$, the highest probability of detection is for the GPS L1 C/A signal. Because the signal is weak, for GPS L1 $\mathrm{C} / \mathrm{A}$, a long coherent integration time is better to accumulate the useful signal. For the same reason, the GPS L5 signal has the lowest performance in terms of probability of detection because the coherent integration time is $10 \mathrm{~ms}$ which is the longest for the other data/pilot signals. Clearly, for Galileo E1 OS and GPS L5, it is better to acquire both components to not suffer from the loss of $3 \mathrm{~dB}$ on the signal power. However, for the GPS L1C signal, it seems to be more interesting to acquire only the pilot component to reduce by one half the computation load and reach the same performance.

TABLE V. AVERAGE PROBABILITY OF DETECTION FOR $K T_{I}=20 \mathrm{MS}$

\begin{tabular}{|c|c|c|c|c|c|}
\hline & \multicolumn{3}{|c|}{$\mathrm{C} / \mathrm{N}_{\mathbf{0}}(\mathrm{dB}-\mathrm{Hz})$} \\
\hline & & & 27 & 30 & 35 \\
\hline \multicolumn{3}{|c|}{ GPS L1 C/A } & $\begin{array}{c}0.55 \\
\mathrm{~T}_{\mathrm{I}}=10 \mathrm{~ms}\end{array}$ & $\begin{array}{c}0.93 \\
\mathrm{~T}_{\mathrm{I}}=5 \mathrm{~ms}\end{array}$ & $\begin{array}{c}1 \\
\forall \mathrm{T}_{\mathrm{I}} \neq 20 \mathrm{~ms}\end{array}$ \\
\hline \multirow{2}{*}{$\begin{array}{l}\text { Galileo } \\
\text { E1 OS }\end{array}$} & \multicolumn{2}{|c|}{1 comp. } & 0.05 & 0.24 & 0.87 \\
\hline & \multicolumn{2}{|c|}{2 comp. } & 0.13 & 0.51 & 0.98 \\
\hline \multirow{3}{*}{$\begin{array}{l}\text { GPS } \\
\text { L5 }\end{array}$} & \multirow{2}{*}{$\begin{array}{c}1 \\
\text { comp. }\end{array}$} & Data & 0.01 & 0.05 & 0.61 \\
\hline & & Pilot & 0.01 & 0.06 & 0.66 \\
\hline & \multicolumn{2}{|c|}{2 comp. } & 0.04 & 0.24 & 0.99 \\
\hline \multirow{3}{*}{$\begin{array}{l}\text { GPS } \\
\text { L1C }\end{array}$} & \multirow{2}{*}{$\begin{array}{c}1 \\
\text { comp. }\end{array}$} & Data & 0.03 & 0.13 & 0.67 \\
\hline & & Pilot & 0.27 & 0.64 & 0.90 \\
\hline & \multicolumn{2}{|c|}{2 comp. } & 0.29 & 0.70 & 0.95 \\
\hline
\end{tabular}

TABLE VI. REQUIRED C/N $\mathrm{N}_{0}$ FOR AN AVERAGE PROBABILITY OF DETECTION OF $95 \% K T_{I}=20 \mathrm{MS}$

\begin{tabular}{|c|c|c|c|c|}
\hline & & & Without data & With data \\
\hline \multicolumn{3}{|c|}{ GPS L1 C/A } & $28.4 \mathrm{~dB}-\mathrm{Hz}$ & $30.3 \mathrm{~dB}-\mathrm{Hz}$ \\
\hline \multirow{2}{*}{$\begin{array}{l}\text { Galileo } \\
\text { E1 OS }\end{array}$} & \multicolumn{2}{|c|}{1 comp. } & $33 \mathrm{~dB}-\mathrm{Hz}$ & $36.8 \mathrm{~dB}-\mathrm{Hz}$ \\
\hline & \multicolumn{2}{|c|}{2 comp. } & $30.9 \mathrm{~dB}-\mathrm{Hz}$ & $33.9 \mathrm{~dB}-\mathrm{Hz}$ \\
\hline \multirow{3}{*}{ GPS L5 } & \multirow{2}{*}{1 comp. } & Data & 34.9 dB-Hz & $38 \mathrm{~dB}-\mathrm{Hz}$ \\
\hline & & Pilot & $34.9 \mathrm{~dB}-\mathrm{Hz}$ & $37.5 \mathrm{~dB}-\mathrm{Hz}$ \\
\hline & \multicolumn{2}{|c|}{2 comp. } & $33 \mathrm{~dB}-\mathrm{Hz}$ & $34.1 \mathrm{~dB}-\mathrm{Hz}$ \\
\hline \multirow{3}{*}{ GPS L1C } & \multirow{2}{*}{1 comp. } & Data & $35.1 \mathrm{~dB}-\mathrm{Hz}$ & $46 \mathrm{~dB}-\mathrm{Hz}$ \\
\hline & & Pilot & $30.3 \mathrm{~dB}-\mathrm{Hz}$ & $41.4 \mathrm{~dB}-\mathrm{Hz}$ \\
\hline & \multicolumn{2}{|c|}{2 comp. } & $29.8 \mathrm{~dB}-\mathrm{Hz}$ & $34.9 \mathrm{~dB}-\mathrm{Hz}$ \\
\hline
\end{tabular}


Now let us interest in the received total $\mathrm{C} / \mathrm{N}_{0}$ for which the average probability of detection is equal to 0.95 and considering a dwell time of $20 \mathrm{~ms}$. The GPS L1 C/A signal is the signal for which the $\mathrm{C} / \mathrm{N}_{0}$ is the lowest to detect with a probability of $95 \%$ when considering or not bit sign transitions. There is a loss of $1.9 \mathrm{~dB}$ (equivalent $\mathrm{C} / \mathrm{N}_{0}$ ) considering bit sign transitions which is low compared to $3 \mathrm{~dB}-\mathrm{Hz}$ for Galileo E1 OS, $4.6 \mathrm{~dB}$ for GPS L5 and $5.1 \mathrm{~dB}$ for GPS L1C. When only one component is used, the degradations can be very high as 10 $\mathrm{dB}$ for GPS L1C.

\section{CONCLUSIONS}

This paper has shown interesting results related to the probability of detection when considering bit sign transitions. This work allows determining the optimal acquisition parameters to maximize the average probability of detection on the bit sign transition location. The first sections provide the expression of the probability of detection for several GNSS signals whichever the total integration time and considering a coherent integration time lesser or equal to the bit duration to avoid several bit sign transitions during the coherent integration interval. These first innovative results take into account the signal structure (probability of bit sign transition on each component, signal power distribution...) and on the acquisition technique on one or two components.

The simulation results highlight the optimal acquisition parameters in function of the considered GNSS signal. Concerning the GPS L1 C/A signal, this work focuses on the best coherent integration time considering bit sign transition. It was shown that a good tradeoff is a coherent integration time of 4, 5 or $10 \mathrm{~ms}$ (not an extremum value). Indeed, when the coherent integration time is too long $(20 \mathrm{~ms})$, the probability of detection is highly degraded by data bit sign transitions. If the coherent integration time is too short, particularly for low $\mathrm{C} / \mathrm{N}_{0}$, even without considering bit sign transition, the signal is hardly acquired.

For data/pilot signals, if one component has more signal power, it is obvious that it should be the component to acquire. In the case of GPS L1C (75\% on the pilot component), the acquisition on both components provides approximately the same probabilities of detection (considering or not bit sign transition) as the acquisition on the pilot component. In this configuration, it is thus a better choice to acquire only the pilot component to reach the same performance and in a reduced computation time and execution load. For data/pilot signals with the same signal power repartition $(50 \%$ on each component), it is preferable to acquire both component to not suffer from signal power loss.

The comparison of GNSS signals acquisition performance highlights that the probability of detection when bit transitions occur is better for the signals with the longer spreading code period. The highest losses (around $5 \mathrm{~dB}$ ) on the required sensitivity to reach a predefined average probability of detection due to bit sign transitions are for signals with the longest spreading code periods (GPS L1C). That means that for long spreading code period signals, the required $C / N_{0}$ is the highest which is the contrary of the case no bit transition.
This work was presented for a dwell time of $20 \mathrm{~ms}$ but it can be extended at any dwell time. In particular, it can be interesting to study for a higher dwell time to acquire weak signals with a high probability of detection. For the GPS L1 $\mathrm{C} / \mathrm{A}$ signal, the choice of the best coherent integration time would then be refined and not depending with the received sensitivity which is generally unknown. For the new signals (data/pilot structure), the bit sign transitions degrade considerably the acquisition performance. Thus, it appears necessary to consider bit sign transition insensitive acquisition method such as $1+1 \mathrm{~ms}$ and DBZPTI [14].

This work can be extended following different axes. The first one consists in validating it on a set of real data. This permits to have a more realistic study on the acquisition performance taking into account other facts which can accentuate or reduce the losses due to bit sign transitions as the code Doppler effect [15]. From the point of view of the acquisition implementation and with an objective close to realtime processing, other aspects can be studied. Knowing that the probability of detection for the acquisition on both components on $K T_{I} \mathrm{~ms}$ is the same as the probability of detection for the acquisition on one component but on $2 K T_{I} \mathrm{~ms}$, it can be interesting to study the computational load for each acquisition technique in order to reduce the execution time but reaching the same acquisition performance.

\section{REFERENCES}

[1] M. Foucras, O. Julien, C. Macabiau, and B. Ekambi, "An Efficient Strategy for the Acquisition of Weak Galileo E1 OS Signals," in Proceedings of the European Navigation Conference 2013 (ENC 2013), Vienna, Austria, 2013.

[2] J. A. Avila-Rodriguez, "On Generalized Signal Waveforms for Satellite Navigation," Ph.D. thesis, University FAF, Munich, Germany, 2008.

[3] Navstar, "GPS Space Segment/User Segment L1C Interface (IS-GPS-800C)." Sep-2012.

[4] E. D. Kaplan and C. Hegarty, Understanding GPS: Principles and Applications, 2nd edition. Artech House, 2005.

[5] Navstar, "GPS Space Segment/Navigation User Interfaces (IS-GPS-200G).” Sep-2012.

[6] J. W. Betz, M. A. Blanco, C. R. Cahn, P. A. Dafesh, C. J. Hegarty, K. W. Hudnut, V. Kasemsri, R. Keegan, K. Kovach, L. S. Lenahan, H. H. Ma, J. J. Rushanan, D. Sklar, T. A. Stansell, C. C. Wang, and S. K. Yi, "Description of the L1C Signal," in Proceedings of the 19th International Technical Meeting of the Satellite Division of The Institute of Navigation (ION GNSS 2006), Fort Worth, TX, USA, 2006, pp. $2080-2091$.

[7] Navstar, "GPS Space Segment/User Segment L5 Interfaces (IS-GPS-705C).” Sep-2012.

[8] European Union, "European GNSS (Galileo) Open Service Signal In Space Interface Control Document (OS SIS ICD) Issue 1." Feb-2010.

[9] H. Al Bitar, "Advanced GPS Signal Processing Techniques for LBS Services," Ph.D. thesis, Institut National Polytechnique de Toulouse, 2007. 
[10] C. O'Driscoll, "Performance Analysis of the Parallel Acquisition of Weak GPS Signals," Ph.D. thesis, National University of Ireland, 2007.

[11] M. Foucras, O. Julien, C. Macabiau, B. Ekambi, and F. Bacard, "Probability of Detection for GNSS Signals with Sign Transitions," IEEE Trans. Aerosp. Electron. Syst., to be submitted in Mal 2014.

[12] RTCA, Inc, “Assessment of Radio Frequency Interference Relevant to the GNSS L1 Frequency Band RTCA/DO235B." 13-Mar-2008.

[13] F. Bastide, O. Julien, C. Macabiau, and B. Roturier, "Analysis of L5/E5 Acquisition, Tracking and Data Demodulation Thresholds," in Proceedings of the 15th International Technical Meeting of the Satellite Division of The Institute of Navigation (ION GPS 2002), Portland, OR, USA, 2002, pp. 2196 - 2207.

[14] M. Foucras, O. Julien, C. Macabiau, and B. Ekambi, "A Novel Computationally Efficient Galileo E1 OS Acquisition Method for GNSS Software Receiver," in Proceedings of the 25th International Technical Meeting of The Satellite Division of the Institute of Navigation (ION GNSS 2012), Nashville, TN, USA, 2012, pp. $365-$ 383.

[15] M. Foucras, O. Julien, C. Macabiau, and B. Ekambi, "Detailed Analysis of the Impact of the Code Doppler on the Acquisition Performance of New GNSS Signals," in Proceedings of the 2014 International Technical Meeting of The Institute of Navigation, San Diego, CA, USA, 2014, pp. $513-524$. 